CARDIOVASCULAR MEDICINE

\title{
Association of endothelial constitutive nitric oxide synthase gene polymorphism with acute coronary syndrome in Koreans
}

\author{
K-W Park, K-H You, S Oh, I-H Chae, H-S Kim, B-H Oh, M-M Lee, Y-B Park
}

Heart 2004;90:282-285. doi: 10.1136/hrt.2002.003616

See end of article for authors' affiliations

Correspondence to:

Dr H-S Kim, Department of Internal Medicine, Seoul National University

College of Medicine, 28

Yongon-dong Chongnogu, Seoul, 1 10-744 Korea; hyosoo@snu.ac.kr

Accepted 28 August 2003

\begin{abstract}
Objective: To examine the effects of two polymorphisms of the endothelial constitutive nitric oxide synthase (ecNOS) gene, $4 a / 4 b(A: B)$ located in intron 4 and Glu298Asp(G:T) located in exon 7, on the development of acute coronary syndromes (ACS).

Methods: 164 patients with ACS and 142 control participants were investigated for genotype and conventional risk factors. Genotype was determined by polymerase chain reaction and restriction fragment length polymorphism analysis.

Results: Genotype and allele frequencies of the A:B polymorphism in the ACS group 10.15:0.85 for $A A+A B: B B, 0.09: 0.91$ for $A: B)$ differed from those in the control group $10.26: 0.74$ for $A A+A B: B B$, $0.15: 0.85$ for $A: B)$. However, genotype and allele frequencies of the $G: T$ polymorphism in the ACS group 10.22:0.78 for TT+TG:GG, 0.11:0.89 for T:G) were similar to those in the control group (0.17:0.83 for TT+TG:GG, 0.09:0.91 for T:G). Multiple logistic regression analysis showed that the non-BB (AA+AB) and the non-BB+GG genotypes were significant protective factors against ACS lodds ratios 0.49 and 0.34 , $95 \%$ confidence intervals 0.26 to 0.93 and 0.14 to 0.83 , respectively). In addition, linear association analysis showed that the percentage of ACS patients was significantly lower in the genotype group non$\mathrm{BB}+\mathrm{GG}$ than in the genotype group $\mathrm{BB}+$ non-GG $(39.6 \%$ v $62.7 \%, \mathrm{p}=0.01)$.

Conclusions: The non-BB genotype of the ecNOS $4 a / 4 b$ gene polymorphism is a protective factor against the development of ACS. The GG genotype of the ecNOS Glu298Asp polymorphism exerts a benefit in addition to the non-BB genotype in the Korean population.
\end{abstract}

$\mathrm{N}$ itric oxide is an important endogenous vasodilator and a key factor in the antiatherosclerotic properties of the endothelium. It regulates vascular smooth muscle cell proliferation and migration, vascular tone, endothelial permeability, and endothelial-leucocyte interaction, and has antithrombotic effects. ${ }^{1-4}$ Because of the pleiotrophic effects of nitric oxide, investigators have tried to identify the link between polymorphisms of the endothelial constitutive nitric oxide synthase (ecNOS) gene and the development of coronary artery disease (CAD).

Among the many reported polymorphisms of the ecNOS gene, two polymorphisms, namely the ecNOS $4 \mathrm{a} / 4 \mathrm{~b}(\mathrm{~A}: \mathrm{B})$ polymorphism located in intron 4 and the Glu298Asp(G:T) polymorphism located in exon 7 , have received much interest with respect to the possible association between such polymorphisms and CAD. Several studies have investigated the relation between ecNOS gene polymorphism and myocardial infarction (MI). Ichihara and colleagues ${ }^{5}$ showed in a Japanese population, which lacked other conventional risk factors, that the ecNOS $4 \mathrm{a}$ allele is an independent risk factor of MI. In another study, the ecNOS 4a/4a homozygote was identified as a smoking dependent risk factor of MI. ${ }^{6}$ In addition, the missense Glu298Asp variant (T allele) has been shown to be associated with MI.

However, previous studies are not without their limitations. Although MI and unstable angina are thought to have the same pathophysiological mechanism, involving a reduction of myocardial oxygen supply due to plaque disruption and associated thrombosis and vasoconstriction, ${ }^{8}$ patients with unstable angina were not included in the study group in previous studies. In addition, whereas several genetic polymorphisms of the ecNOS gene exist, the majority of previous studies have focused on the effect of one genetic polymorphism and, as a result, interactions between different polymorphisms have not been investigated. In the present study, we sought to evaluate the effects of the two most investigated polymorphisms of ecNOS (that is, the ecNOS 4a/ 4b and Glu298Asp polymorphisms) on the development of acute coronary syndromes (ACS) and to find out whether the polymorphisms interact with each other.

\section{METHODS \\ Study participants}

Three hundred and six patients, 164 with ACS (106 with acute MI and 58 with unstable angina) and 142 controls, all of whom gave consent to DNA analysis, were enrolled for the study at Seoul National University Hospital. Acute MI was diagnosed in patients with typical chest pain, ECG changes, and an increase in creatine kinase of more than twice the upper limits of normal. Unstable angina was diagnosed clinically according to Braunwald's definition. ${ }^{9}$ The control group consisted of 142 genetically unrelated Koreans (71 women and 71 men) who did not have significant CAD by coronary angiography. Significant CAD was defined angiographically as a transluminal narrowing of $>50 \%$ after intracoronary infusion of glyceryl trinitrate. Conventional risk factors of CAD were recorded: plasma lipid concentrations, body mass index, and the presence of hypertension (systolic blood pressure $>140 \mathrm{~mm} \mathrm{Hg}$, diastolic blood pressure $>90 \mathrm{~mm} \mathrm{Hg}$, or both) or diabetes mellitus.

\footnotetext{
Abbreviations: $A C S$, acute coronary syndromes; $C A D$, coronary artery disease; ecNOS, endothelial constitutive nitric oxide synthase; MI, myocardial infarction
} 
Patients who had smoked more than a third of a pack a day for more than one year were considered to be smokers.

\section{Gene analysis}

DNA was prepared from blood leucocytes by standard methods. ${ }^{10}$ Target regions of the ecNOS gene in extracted DNA samples were amplified by polymerase chain reaction according to previously reported protocols. ${ }^{67}$ Briefly, for the ecNOS4a/4b polymorphism, the forward primer used was 5-AGG CCC TAT GGT AGT GCC TTT-3 and the reverse primer 5-TCT CTT AGT GCT GTG GTC AC-3. For the Glu298Asp polymorphism, the forward primer was 5-AAG GCA GGA GAC AGT GGA TGG A-3 and the reverse primer 5-CCC AGT CAA TAA TTT GGT GAT CA-3. A volume of $50 \mu \mathrm{l}$ was used for each polymerase chain reaction, which contained $1 \mu \mathrm{M}$ of each primer, $200 \mu \mathrm{M}$ of each dNTP, $1.5 \mathrm{mmol} / \mathrm{l} \mathrm{MgCl}_{2}$, $50 \mathrm{mmol} / \mathrm{L} \mathrm{KCl}, 10 \mathrm{mmol} / \mathrm{l}$ Tris- $\mathrm{HCl}$ at $\mathrm{pH} \mathrm{8.3,} \mathrm{and} 1.6 \mathrm{U}$ Taq polymerase (Boehringer Mannheim Biochemica, Mannheim, Germany) with $1 \mu \mathrm{g}$ of genomic DNA. The conditions of amplification were denaturing at $94^{\circ} \mathrm{C}$ for five minutes, 35 cycles at $94^{\circ} \mathrm{C}$ for one minute, $56^{\circ} \mathrm{C}$ for one minute, $72^{\circ} \mathrm{C}$ for two minutes, and finally termination at $72^{\circ} \mathrm{C}$ for five minutes.

The polymerase chain reaction products of the ecNOS4a/4b polymorphism were electrophoresed in 3\% agarose gel (NuSieve GTG agarose, FMC, Rockland, Maine, USA) and visualised by ethidium bromide staining. The polymerase chain reaction products of the Glu298Asp polymorphism were digested with the restriction enzyme BanII (Boehringer Mannheim). The digested products were also electrophoresed in 3\% agarose gel (NuSieve GTG agarose, FMC) and visualised by ethidium bromide staining.

\section{Statistical analysis}

Case-control differences in clinical and biological continuous variables were analysed with a general linear model. Categorical variables were evaluated with the $\chi^{2}$ test. The observed frequencies of the genotypes were compared with the frequencies expected under the Hardy-Weinberg equilibrium by $\chi^{2}$ tests. To evaluate the combined effects of the two polymorphisms, the genotypes were grouped as $\mathrm{BB}+$ non$\mathrm{GG}(\mathrm{TT}+\mathrm{TG})$, $\mathrm{BB}+\mathrm{GG}$, non-BB(AA+AB)+non-GG, and non$\mathrm{BB}+\mathrm{GG}$. Linear association analysis was used to identify any relations between the genotype groups and the percentage of patients with ACS in each group. We hypothesised that the prevalence of ACS would be higher among patients with the $\mathrm{BB}$ and non-GG genotypes than among patients with the non-BB and GG genotypes. Multiple logistic regression analysis was used to estimate the contributions made by the ecNOS4a/4b and Glu298Asp polymorphisms to ACS. SPSS for Windows version 10.0 (SPSS Inc, Chicago, Illinois, USA) was used for statistical analysis and $\mathrm{p}<0.05$ was considered significant.

\section{RESULTS}

\section{Clinical characteristics}

Table 1 summarises the clinical characteristics of patients enrolled in the study. Mean (SD) age, body mass index, the presence of hypertension, and mean (SD) plasma concentrations of total cholesterol, low density lipoprotein cholesterol, and high density lipoprotein cholesterol were similar between the ACS group and control group. There were significantly higher percentages of men, smokers, and patients with diabetes mellitus in the ACS group $(p<0.05)$. The baseline triglyceride concentrations were higher in the ACS group $(p<0.05)$.

\section{ecNOS gene polymorphism and ACS}

Table 2 shows the distribution of genotypes and the prevalence of alleles in the control group and the ACS group.
Table 1 Clinical characteristics of patients with acute coronary syndromes (ACS)

\begin{tabular}{|c|c|c|}
\hline & ACS group & Control group \\
\hline Number & 164 & 142 \\
\hline Sex (male/female)* & $122 / 42$ & $71 / 71$ \\
\hline Age (years) & $58.0(9.4)$ & $56.2(9.8)$ \\
\hline BMI $\left(\mathrm{kg} / \mathrm{m}^{2}\right)$ & $24.4(2.6)$ & $25.0(3.4)$ \\
\hline Smoking* & $59 \%$ & $28 \%$ \\
\hline Diabetes mellitus* & $25 \%$ & $13 \%$ \\
\hline Hypertension & $44 \%$ & $36 \%$ \\
\hline TC (mmol/l) & $5.30(0.97)$ & $5.13(0.98)$ \\
\hline TG $(g / /)^{*}$ & $1.56(0.86)$ & $1.33(0.69)$ \\
\hline LDL-C (mmol/l) & $3.48(0.90)$ & $3.28(0.87)$ \\
\hline $\mathrm{HDL}-\mathrm{C}(\mathrm{mmol} / \mathrm{l})$ & $1.09(0.28)$ & $1.12(0.31)$ \\
\hline
\end{tabular}

BMI, body mass index; HDL-C, high density lipoprotein cholesterol; LDLC, low density lipoprotein cholesterol; TC, total cholesterol; TG, triglyceride.

${ }^{*} \mathrm{p}<0.05$.

Table 2 Genotype distribution and allele prevalence of ecNOS gene polymorphism

\begin{tabular}{|c|c|c|c|}
\hline & ACS group & Control group & p Value \\
\hline \multicolumn{4}{|c|}{ Genotype } \\
\hline $\mathrm{AA}$ & $4(2.4 \%)$ & $7(4.9 \%)$ & $<0.05$ \\
\hline$A B$ & 21 (12.8\%) & $30(21.1 \%)$ & $<0.05$ \\
\hline $\mathrm{BB}$ & $139(84.8 \%)$ & $105(74 \%)$ & $<0.05$ \\
\hline$\pi$ & $1(0.6 \%)$ & $2(1.4 \%)$ & NS \\
\hline TG & $35(21.3 \%)$ & $22(15.5 \%)$ & NS \\
\hline GG & $128(78.0 \%)$ & $118(83.1 \%)$ & NS \\
\hline \multicolumn{4}{|l|}{ Allele } \\
\hline A & $9 \%$ & $15 \%$ & $<0.05$ \\
\hline$B$ & $91 \%$ & $85 \%$ & $<0.05$ \\
\hline $\mathrm{T}$ & $11 \%$ & $9 \%$ & NS \\
\hline G & $89 \%$ & $91 \%$ & NS \\
\hline \multicolumn{4}{|c|}{$\begin{array}{l}\text { Genotypes of the endothelial constitutive nitric oxide synthase (ecNOS) } \\
4 a / 4 b \text { polymorphism: } A A, A B, B B \text {. Genotypes of the ecNOS Glu298Asp } \\
\text { polymorphism: TT, TG, GG. } \\
\text { NS, not significant. }\end{array}$} \\
\hline
\end{tabular}

The prevalence of the ecNOS $4 \mathrm{a}$ allele was $15 \%$ and of the Glu298Asp T allele 9\% in the control group, which was comparable with a previous report on Koreans. ${ }^{11}$ When the control group and the ACS group were compared, a significant difference was found in the distribution of the ecNOS4a/4b genotype and allele prevalence (table 2); the ecNOS4a allele was more common in the control group (15\% $v 9 \%, \mathrm{p}=0.019)$. In the analysis of the dominant effects of the ecNOS4a (A) allele, the prevalence of the non-BB genotype $(\mathrm{AA}+\mathrm{AB})$ was found to be significantly higher in the control group than in the ACS group (26\% $v 15.2 \%$, $\mathrm{p}<0.05)$. However, the genotype distributions and allele prevalences of the Glu298Asp polymorphism were not significantly different between the control and ACS groups. When the genotypes of the two polymorphisms were combined as BB+non-GG(TT+TG), BB+GG, non$\mathrm{BB}(\mathrm{AA}+\mathrm{AB})+$ non- $\mathrm{GG}$, and non-BB+GG, a significant difference was found in genotype distribution and a significant linear trend was observed in terms of the percentage of patients with ACS between the combined genotype groups. The proportion of patients with ACS was significantly lower in the genotype group non- $\mathrm{BB}+\mathrm{GG}$ than in the genotype group $\mathrm{BB}+$ non-GG $(39.6 \% \vee 62.7 \%, \mathrm{p}=0.01)$ (table 3 , fig 1 ).

To determine whether the polymorphisms were independent risk factors or protective factors of ACS, we performed multiple logistic regression analysis with conventional risk factors. The results showed that the non-BB $(A A+A B)$ genotype was an independent protective factor against ACS (odds ratio $0.49,95 \%$ confidence interval 0.26 to 0.93 ; 
Table 3 Combined analysis of occurrence of ecNOS4a/ $4 \mathrm{~b}$ and Glu298Asp polymorphisms in the ACS and control groups

\begin{tabular}{lll}
\hline Combined genotypes & ACS group & Control group \\
\hline BB+non-GG & $32(62.7 \%)$ & $19(37.3 \%)$ \\
BB+GG & $107(55.4 \%)$ & $86(44.6 \%)$ \\
Non-BB+non-GG & $4(44.4 \%)$ & $5(55.6 \%)$ \\
Non-BB+GG & $21(39.6 \%)$ & $32(60.4 \%)$ \\
\hline
\end{tabular}

Linear by linear association $p=0.01$

$p<0.05)$. Furthermore, the non-BB+GG genotype had a lower odds ratio than the non-BB genotype alone (table 4) (odds ratio $0.34,95 \%$ confidence interval 0.14 to 0.83 , $\mathrm{p}<0.05)$, thus showing a further benefit in terms of protection against ACS. In this model, other independent risk factors of ACS were smoking, diabetes mellitus, male sex, hypercholesterolaemia, and increasing age.

\section{DISCUSSION}

Our study shows that the ecNOS4a/4b polymorphism is of pathophysiological significance in ACS, at least in this Korean population. The results show that the non-BB genotype of the ecNOS4a/4b polymorphism has a protective effect against the development of ACS and the GG genotype of the ecNOS Glu298Asp polymorphism exerts an additive beneficial effect on the non-BB genotype. These findings imply that polymorphisms of the ecNOS gene may have significant roles in the pathogenesis of ACS.

\section{ecNOS gene polymorphism and ACS}

Investigations into the relation between ecNOS gene polymorphism and CAD have given various and sometimes contradictory results. Uwabo ${ }^{12}$ showed that the ecNOS4a allele is associated with essential hypertension and may be a genetic marker of the disease. Ichihara $e t$ al $l^{5}$ showed that the ecNOS $4 \mathrm{a}$ allele is an independent risk factor of MI, and Wang et $a l^{6}$ reported that the ecNOS $4 \mathrm{a} / 4$ a homozygote is a smoking dependent risk factor of CAD. However, studies by Hibi et $a l^{13}$ and Jeerooburkhan et $a l^{14}$ found no association between the ecNOS $4 \mathrm{a} / 4 \mathrm{~b}$ polymorphism and acute MI. Likewise, the Glu298Asp polymorphism of the ecNOS gene has been shown to be associated with acute MI in some studies $^{713}$ but others found no association between the Glu298Asp polymorphism and premature CAD. ${ }^{15}$

In the present study, we found that the ecNOS4a allele exerts a protective effect against ACS and that this effect is not attenuated but rather potentiated by the GG genotype of the Glu298Asp polymorphism, which by itself was not found to be a significant protective factor against ACS. To the best of our knowledge, this is a novel finding, which contradicts previous reports. The discrepancy between the results of previous studies and ours may be explained as follows. Firstly, the study populations in previous studies deviated from the Hardy-Weinberg equilibrium and therefore the results obtained could not be easily applied to the general population. In the report by Wang et al, ${ }^{6}$ the genotype distribution of the study group (CAD patients) deviated from the Hardy-Weinberg equilibrium $\left(\chi^{2}=5.41, p=0.035\right)$. Furthermore, the observed prevalence of the $4 a / 4 a$ genotype in the subgroup with no significantly diseased vessels was zero, while the expected prevalence under the HardyWeinberg equilibrium was 2.5. In addition, the allele prevalence and distribution of the patient group were not significantly different from those of the control group (4a/4b allele prevalence was $0.144 / 0.857$ in patients with CAD and $0.170 / 0.830$ in the control group; $p>0.05)$. The study showed a difference in the genotype distribution within the

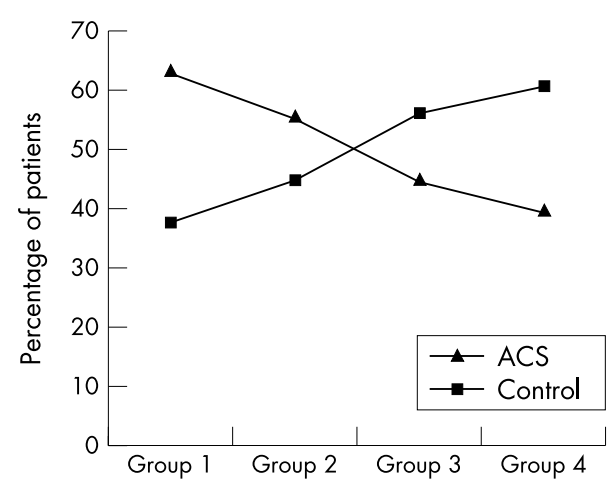

Figure 1 Linear by linear association of the combined genotypes of the endothelial constitutive nitric oxide synthase (ecNOS) polymorphism. Group 1: BB+non-GG genotype; group 2: $B B+G G$ genotype; group 3: non-BB+non-GG genotype; group 4: non- $B B+G G$ genotype. The proportion of patients with ACS was significantly lower in the genotype group non-BB+GG than in the genotype group $B B+$ non- $G G(p=0.01)$.

patient group — that is, between patients with no significantly diseased vessels and patients with one or more significantly diseased vessels. However, even this was no longer significant when lifetime smoking dose was entered into the analysis. The only significant finding was that, in smokers, there was a significant correlation between those with one or more significantly diseased vessels and the ecNOS polymorphism. Secondly, the patient selection was different-that is, unstable angina, a very important and common disease that shares the same pathophysiological mechanism as MI, was not examined in the study group. In studies by Ichihara et $a l^{5}$ and Hibi et $a l^{13}$, the study groups consisted only of patients with MI. If ecNOS polymorphism contributes significantly to the pathogenesis of MI, as previous investigators think it does, it should contribute similarly to the development of unstable angina. Since previous studies did not examine unstable angina, the data in these studies cannot be generalised to patients with ACS.

In contrast, not only was the genotype distribution of the ACS group and the control group in our study within HardyWeinberg equilibrium, but our results also showed a significant difference in both genotype distribution and allele prevalences between the two groups. Furthermore, the study group not only consisted of MI patients but also included patients with unstable angina. In addition, although our findings seem new and in some ways contradictory to previous results, a number of studies support our findings indirectly. For example, in white patients, nitric oxide metabolites were found to be significantly higher in the $4 \mathrm{a}$ / 4a genotype, which suggests a higher concentration of basal nitric oxide release in the $4 \mathrm{a} / 4 \mathrm{a}$ genotype. ${ }^{16}$ Moreover, a reduction in basal nitric oxide release has been reported to predispose to hypertension, thrombosis, vasospasm, and atherosclerosis. ${ }^{17}$ In Koreans, the $4 \mathrm{a}$ allele has also been associated with higher concentrations of nitric oxide metabolites, although the association was significant only in hypertensive patients with CAD in one study ${ }^{11}$ and associated with higher nitric oxide metabolite concentrations in smokers in another study. ${ }^{18}$ The effect of the Glu298Asp polymorphism on nitric oxide concentrations is also unclear. Although no previous study has documented the exact role of the polymorphism on the plasma concentration of nitric oxide metabolites, previous studies have shown that the $\mathrm{T}$ allele is associated with impaired endothelial function and thus is suspected to be associated with a reduction in nitric oxide production. ${ }^{19} 20$

The exact mechanism by which the ecNOS4a/4b gene polymorphism affects the pathogenesis of ACS is not known. 
Table 4 Multiple logistic regression analysis of the effect of the ecNOS gene polymorphism on ACS

\begin{tabular}{llll}
\hline & Odds ratio & $95 \% \mathrm{Cl}$ & $\mathrm{p} \mathrm{Value}$ \\
\hline Smoking & 2.781 & 1.458 to 5.305 & $<0.05$ \\
Diabetes mellitus & 2.651 & 1.335 to 5.262 & $<0.05$ \\
Sex (male/female) & 2.215 & 1.130 to 4.431 & $<0.05$ \\
Hypercholesterolaemia* & 1.785 & 1.051 to 3.032 & $<0.05$ \\
Age & 1.480 & 1.118 to 1.960 & $<0.05$ \\
Hypertension & 1.116 & 0.687 to 1.979 & $\mathrm{NS}$ \\
non-B/B & 0.489 & 0.257 to 0.928 & $<0.05$ \\
non-B/B+G/G† & 0.340 & 0.140 to 0.827 & $<0.05$ \\
\hline
\end{tabular}

${ }^{*}$ Total cholesterol $>6.15 \mathrm{mmol} / \mathrm{l}$; †odds ratio to $B / B+$ non-G/G genotype.

$\mathrm{Cl}$, confidence interval.

Previous studies have shown that the ecNOS gene polymorphism is responsible for variations in the genetic control of the plasma concentration of nitric oxide metabolites. ${ }^{17} 21$ Moreover, nitric oxide can inhibit vascular smooth cell proliferation, ${ }^{1}$ which is responsible for the synthesis and assembly of the macromolecules that strengthen the fibrous cap. Therefore, there is a possibility that the inhibition of smooth muscle cell proliferation with changing ecNOS activity determined by ecNOS genotype contributes to the formation of a friable fibrous cap. ${ }^{22}$

\section{Limitations of this study}

The first limitation concerns the sample size of the study. We examined the distribution of the ecNOS gene polymorphisms in 142 control subjects and 164 patients, which is not a large sample. However, the genotype prevalences of the polymorphisms in each group were in Hardy-Weinberg equilibrium, which we believe allows us to exclude the possibility of a selection bias. Also, the sample size was large enough to give allele prevalences of the control group that were comparable with previous published data on Koreans. ${ }^{11}$ Another limitation is that patients in the controls were not healthy volunteers representative of the general population and they had various atypical symptoms. However, the control participants were confirmed by coronary angiography to be free of significant coronary stenosis. Lastly, the intermediate phenotypes of the polymorphism were not studied. Therefore, this study goes only as far as showing a significant association between ecNOS polymorphism and ACS.

In conclusion, our study shows that the non-BB genotype of the ecNOS $4 \mathrm{a} / 4 \mathrm{~b}$ gene polymorphism is a protective factor against the development of ACS and that the GG genotype of the ecNOS Glu298Asp polymorphism exerts an additive beneficial effect on the non-BB genotype in the Korean population. These findings imply that, although the mechanism underlying the association between the ecNOS gene polymorphism and ACS has so far remained elusive, the genetic background controlling nitric oxide may be associated with the pathogenesis of ACS.

\section{ACKNOWLEDGEMENTS}

This study was supported by grants to Dr Hyo Soo Kim from the Korea Health 21 R\&D project, the Ministry of Health \& Welfare, Republic of Korea (02-PJ10-PG8-EC01-0026 to Dr H-S Kim), and from the Korea Science and Engineering Foundation (KOSEF) through the aging and apoptosis research centre at Seoul National University.

\section{Authors' affiliations \\ ${ }^{*} \mathrm{~K}-\mathrm{W}$ Park, K-Hoon You, *S Oh, *I-H Chae, *H-S Kim, *B-H Oh, *M-M Lee, *Y-B Park, Cardiovascular Laboratory, Clinical Research Institute,} Seoul National University Hospital, Seoul, Korea
*Also the Department of Internal Medicine, Seoul National University College of Medicine, Seoul, Korea

\section{REFERENCES}

1 Sakar R, Web RC, Stanley JC. Nitric oxide inhibition of endothelial cell mitogenesis and proliferation. Surgery 1995;118:274-9.

2 Dubey RK, Jackson EK, Luscher TF. Nitric oxide inhibits angiotensin II-induced migration of rat smooth muscle cell. J Clin Invest 1995;96:141-9.

3 Draijer R, Astma DE, van der Laarse A. c-GMP and nitric oxide modulate thrombin induced endothelial permeability: regulation via different pathways in human aortic and umbilical vein endothelial cells. Circ Res 1995:76:199-208.

4 Gauthie TW, Scalia R, Murohara T. Nitric oxide protects against leukocyteendothelium interactions in the early stages of hypercholesterolemia. Arterioscler Thromb Vasc Biol 1995; 15:1652-9.

5 Ichihara S, Yamada Y, Fujimura T. Association of a polymorphism of the endothelial constitutive nitric oxide synthase gene with myocardial infarction in the Japanese population. Am J Cardiol 1998;81:83-6.

6 Wang XL, Sim AS, Bandenhop RF. A Smoking-dependent risk of coronary artery disease associated with a polymorphism of the endothelial nitric oxide synthase gene. Nat Med 1996:2:41-5.

7 Shimasaki Y, Yasue H, Yoshimura M. Association of the missense Glu298Asp variant of the endothelial nitric oxide synthase gene with myocardial infarction. J Am Coll Cardiol 1998;31:1506-10.

8 Theroux $\mathbf{P}$, Fuster $\mathrm{V}$. Acute coronary syndrome: unstable angina and nonQ wave myocardial infarction. Circulation 1998;97:1195-206.

9 Braunwald E. Unstable angina: a classification. Circulation 1989;80:410-4.

10 Miller SA, Dykes DD, Polesky HF. A simple salting out method for extracting DNA from human nucleated cells. Nucleic Acids Res 1988;16:12-5.

11 Yoon Y, Song J, Hong SH, et al. Plasma nitric oxide concentrations and nitric oxide synthase gene polymorphisms in coronary artery disease. Clin Chem 2000;46:1626-30.

12 Uwabo $\mathrm{J}$. Association of a variable of tandem repeats in the endothelial constitutive nitric oxide synthase gene with essential hypertension in Japanese. Am J Hypertens 1998;11:125-8.

13 Hibi K, Ishigami T, Tamura K. Endothelial nitric oxide synthase gene polymorphism and acute myocardial infarction. Hypertension 1998;32:521-6.

14 Jeerooburkhan N, Jones LC, Bujac S. Genetic and environmental determinants of plasma nitrogen oxides and risk of ischemic heart disease. Hypertension 2001;38:1054-61.

15 Nassar BA, Bevin LD, Johnstone DE. Relationship of the Glu298Asp polymorphism of the endothelial nitric oxide synthase gene and early-onset coronary artery disease. Am Heart J 2001; 142:586-9.

16 Wang XL, Mahaney MC, Sim AS. Genetic contribution of the endothelial constitutive nitric oxide synthase gene to plasma nitric oxide levels. Arterioscler Thromb Vasc Biol 1997;17:3147-53.

17 Nava E, Noll G, Luscher TF. Nitric oxide in cardiovascular disease. Ann Med 1995;27:343-51

18 Yoon S, Moon J, Shin C, et al. Smoking status-dependent association of the 27 -bp repeat polymorphism in intron 4 of endothelial nitric oxide synthase gene with plasma nitric oxide concentrations. Clin Chim Acta 2002;324:113.

19 Savvidou MD, Vallance PJ, Nicolaides KH, et al. Endothelial nitric oxide synthase gene polymorphism and maternal vascular adaptation to pregnancy. Hypertension 2001;38:1289-93.

20 Leeson CP, Hingorani AD, Mullen MJ, et al. Glu298Asp endothelial nitric oxide synthase gene polymorphism interacts with environmental and dietary factors to influence endothelial function. Circ Res 2002;90:1153-8.

21 Tsukada T, Yokoyama K, Arai T. Evidence of association of the ecNOS gene polymorphism with plasma NO metabolite levels in humans. Biochem Biophys Res Commun 1998;245:190-3.

22 Libby P. molecular bases of the acute coronary syndrome. Circulation 1995;91:2844-50 